\title{
Regina Igel
}

\section{Os novos escritores brasileiros-judeus: geração dos anos 70}

Este ensaio se propõe examinar obras de escritores brasileiros judeus, publicadas a partir de 1990. Foi a partir de então que a geração de filhos de imigrantes, ao alcançarem maturidade etária, começaram a revelar seus talentos literários. Nesta altura, estamos lendo trabalhos de jovens literatos pertencentes à geração dos descendentes dos expatriados, que foram acolhidos no país onde estabeleceram suas famílias. ${ }^{1}$ Esta geração a que vou aludir, por uma seleção de nomes e algumas de suas obras, nas próximas páginas é nascida, escolarizada, criada e instruída no Brasil. O mundo ficcional estampado na sua escrita resulta da sua vivência e observações como filhos da terra e também da sua convivência com seus predecessores (pais, avós, parentes) seja por contato pessoal, seja por intermédio de lembranças, transmitidas por histórias, fotos, desenhos e outros meios similares e tradicionais de transmissão de vida. Portanto, enquanto se pode observar que a matriz cultural persiste nos seus escritos, há um mundo novo desvendado por esses escritores brasileiros judeus, imbuído de atmosfera local e linguagem familiar e contemporânea. Não prescindindo de suas raízes históricas, o cenário físico que se impõe inclui rua e casa, Cidade e campo, o Brasil e o exterior. Nesta variedade ambiental, escritores resgatam ou rejeitam tradições, estipulam a interação judaicanão judaica e estabelecem uma cosmovisão particular e instigante do mundo circundante.

O historiador e folclorista Joaquim Ribeiro observou: "O brasileiro não existe. Existem, sim, os brasileiros" (Ribeiro 1977: 3). Reci-

1 Na obra Imigrantes judeus - escritores brasileiros ( $O$ componente judaico na literatura brasileira), da autora do presente ensaio, são extensivamente examinadas certas características que tipificam a primeira geração de escritores judeus no Brasil. Se eu fosse escrever novo livro sobre a importância da literatura escrita por judeus brasileiros no Brasil de hoje, não teria lugar a palavra 'imigrantes' no seu título, pois o cenário literário brasileiro judaico está preenchido por seus descendentes. (Para reflexões sintetizadas sobre o mesmo assunto, v. Igel 2000.) 
procamente, não se pode dizer que exista "o escritor judeu" (ou a escritora judia), mas sim escritores que estampam na sua escrita suas origens e convivência judaicas com tantas variedades quanto se puderem expressar estilisticamente. No entanto, há uma base comum entre ficcionistas, judeus e não-judeus, e esta é a inclinação pelos mesmos rituais, em graus diferentes de acuidade, que atraem a todos os que se dedicam a escrever ficção: preocupação pela trama, cuidados com o idioma e interesse em manter a atenção de leitores. Cada um dos escritores visados aqui explora essa base em graus diferentes e, no que diz respeito a possíveis influências que terão recebido e filtrado em suas obras, as mesmas podem ter ou não ter liames étnicos ou religiosos. $\mathrm{O}$ conjunto de impressões, reflexões e emoções como espraiadas pelas obras representativas do acervo ficcional brasileiro judeu, no entanto, espelha e registra uma convivência específica, no caso, a convivência judaica.

Tal se encontra na obra de Cíntia Moscovich. ${ }^{2}$ Como o seu conterrâneo Moacyr Scliar, Cíntia focaliza judeus principalmente num entorno urbano. Seu predecessor literário iniciou um roteiro judaico onde se encontram certos valores, hábitos e reflexões que podem ser atribuídos aos judeus do Brasil e que os distinguem de outras comunidades de imigrantes ou de seus descendentes. Moscovich penetrou por esta trilha, descobrindo, revolvendo e analisando alguns elementos arraigados na comunidade judaica e fortalecidos pelo conservantismo brasileiro. A variedade de situações recortadas em grande parte de sua obra pode acontecer com membros de uma família da classe média brasileira localizada, geralmente, num centro cosmopolita como Porto Alegre. Uma das características de sua literatura é a forma como ela se manifesta como narradora da vida corriqueira urbana. Em diversas situações, autora e narradora se identificam como a mesma persona, seja por dados biográficos conhecidos pelo público, seja por sua própria confissão. Ocorre também que Cíntia é jornalista por formação

2 Cíntia Moscovich nasceu em 1958 no Rio Grande do Sul, e surgiu como escritora em 1996, com o livro de contos $O$ reino das cebolas, logo indicado ao Prêmio Jabuti; dois anos mais tarde, em 1998, publicou duas obras: a novela Duas iguais e os contos Anotações durante o incêndio, que recebeu o Prêmio Açorianos; seu terceiro livro de contos, Arquitetura do arco-iris (2004), recebeu dois prêmios: o Portugal Telecom e o Jabuti de 2005; e em 2006, publicou o romance Por que sou gorda, mamãe? 
profissional, o que é perceptível em sua destreza em manipular a língua portuguesa como usada no Brasil. Dentro de uma linguagem de comunicação direta, não afetada por malabarismo léxico, simples e ao nível coloquial, Cíntia também aplica gírias do momento. Suas expressões pela voz narrativa são elaboradas numa linguagem afetivoirônica, beirando compaixão, humor e sarcasmo.

Assim como Scliar é apontado como o iniciador contemporâneo de uma linhagem literária que se designa como "étnica", é possível dizer que a autora esteja fazendo escola, também nesta mesma linha. Neste aspecto, ambos se parecem, embora sejam claramente diferentes na sua armação ficcional. As similaridades se baseiam no alto sentido de humor que penetra pela ficção de ambos e pelo tratamento inequívoco e palpável de estratos da sociedade judaica brasileira, como representada na geografia sulina do país. As diferenças se notam na escolha de cenografia, digamos assim, para o entrosamento dos personagens: enquanto Scliar tende a incluir imagens surrealistas nas suas tramas domésticas, Cíntia percorre um traçado realista, plantado no chão de um cotidiano facilmente assimilado pelo leitor médio aquele que não tem intensa prática ou habilidade em abstrair-se da realidade e criar um mundo suprarreal, como pedem os personagens de Scliar.

Como fez o decano da literatura judaica brasileira, além do humor e da ironia, inserem-se nas obras de Cíntia Moscovich reflexões, rebeldias, questionamentos, teimosias, auto-análise, às vezes evidentes, outras, escamoteadas. Exemplo de uma parcela desta cornucópia de efeitos pode ser visto no conto "O reino das cebolas", onde ela augura que uma dona de casa perceba a mágica de existir, superando o ato de cortar uma cebola e entregando-se a uma atividade lúdica com um bebê, sentada no tapete da casa, para chegar à altura da criança e com ela aprender algo mais (Moscovich 1996: 89-91). No conto "A grande e invisível África", a autora revela que foi na praia de Capão da Canoa que ela descobriu algumas certezas, que a guiaram nas suas montagens imaginárias. Uma delas foi dada por seu pai de que, se alguém nadasse em linha reta pelo mar adentro, daria com os costados na África (Moscovich 2000: 54). Aquela praia onde se plantou tal "certeza" já fora "desvendada" por Moacyr Scliar, como um dos pontos favoritos da comunidade judaica para o lazer. A respeito do local, o escritor observou: "Os cento e trinta quilômetros de boas estradas que 
hoje levam àquele balneário não existiam em 1934, época em que as pessoas da coletividade israelita começaram lá a veranear" (Scliar 2000: 53-54). Foi naquela mesma praia que teve lugar a "batalha de Capão da Canoa", que Scliar inseriu no seu romance $A$ guerra no bom fim, comandada por um garoto judeu na vanguarda de personagens fictícios das histórias em quadrinhos, contra os nazistas que ameaçavam invadir as suas areias.

A inserção de situações relativas a judeus no Rio Grande do Sul, revitalizada por Moacyr Scliar, foi reinforçada não só por Cíntia Moscovich, mas por outros novos escritores. Um grupo deles se terá inspirado nesses dois narradores e na sua própria convivência judaica quanto à temática, obviamente coordenando seu material ficcional de acordo com sua linguagem, seus personagens e perspectivas do seu entorno. $\mathrm{Na}$ altura desta escrita, deparamos com alguns dos escritores que incluem uma fabulação judaica a seus textos, surgidos depois de 1990: Adriana Armony, Tatiana Levy Salem, Leandro Sarmatz e Rafael Bán Jacobsen. Complementando (ou não) esta lista, talvez emergindo como judeu temporão, estaria o septuagenário cantor, poeta e compositor Jorge Mautner. ${ }^{3}$

Adriana Armony, carioca nascida em 1969, é doutora em Letras pela Universidade Federal do Rio de Janeiro. Sua tese versou a obra do dramaturgo brasileiro Nelson Rodrigues, que se tornou tópico do seu primeiro romance, A fome de Nelson (2002). Três anos mais tarde, publicou Judite no país do futuro (2005), que é o que nos interessa nesta comunicação. Este romance é um roteiro geográfico e existencial da personagem Judite, nascida na cidade de Tsfat, em Israel, ao final do regime otomano (1917) (Armony 2008). Como se fosse uma espécie de tributo à obra de Stefan Zweig, Brasil, país do futuro (Brasilien, ein Land der Zukunft; 1941) a história de Judite se desenvolve em vários países, tendo o Brasil como o destino final de sua família de

3 Nascido no Rio de Janeiro em 1941, a obra literária de Jorge Henrique Mautner conta com um livro de memórias, O filho do Holocausto (2006), onde apresenta seu pai judeu, sua mãe católica e seu padrasto evangélico, três refugiados europeus abarcando uma só família depois do divórcio dos seus pais (o narrador conviveu com os três em São Paulo). Mais inclinado a contar sua própria trajetória musical e de crítico da sociedade neste trabalho, Mautner se apoia em ecos dos eventos do Holocausto, um artifício acoplado a reflexões sobre convivência, preconceitos e sua revolução artística, intentada na década dos anos 60s. (Para mais informações sobre o autor, v. <www.jorgemautner.com.br>). 
expatriados europeus. Passaram por grandes privações com a ausência do pai, que fora para o Brasil prometendo buscar a família quando tivesse meios para isto. $O$ envio das parcas quantias que ele conseguia fazer foi suspenso com a Primeira Guerra Mundial (1914-1918). Sem o chefe, a família permaneceu em Israel, então território dos ingleses, onde sua mãe, sempre doente e fraca, mais os cinco filhos, sofreram humilhações e imposições de parentes, abandono e negligência de parte dos britânicos, então donos da região, que fora arrebatada dos otomanos.

O que mais se salienta nesta obra é o entrelaçamento fiel e constante entre a protagonista e sua família, sua atitude perante o surgimento do Sionismo, vocação para os estudos e sua extrema paixão pela vida. Foi empregada doméstica - ou quase escrava - , combatente durante os primeiros anos do estabelecimento de Israel, estudou contabilidade e trabalhou como contadora, até finalizar sua trajetória profissional como professora de hebraico ("mora") no Brasil. Representando heroínas anônimas da história do judaísmo contemporâneo, a moça Judite passou por diversos quadros ambientais e transformações pessoais que moldaram seu caráter, mas não a prepararam para suas decepções. (Guardadas as devidas proporções e demais elementos diferenciais, o mesmo se terá passado com Stefan Zweig, que não tolerou as desilusões de ordem pessoal e se suicidou na cidade de Petrópolis, onde o governo brasileiro o havia acolhido.)

A narrativa começa em 1916 e termina em 2004, pela voz de Judite, a protagonista, ao longo de lembranças que foram marcantes na sua vida e na história do mundo que ela conheceu. Ao final, expressa desilusão ao ver que os laços que sustentaram seu grupo familiar durante a juventude e grande parcela de sua vida adulta se diluíam diante dos seus olhos. Da parte de seus netos não havia interesse em sua trajetória, deliberadamente negligenciada por eles. Sua história não lhes dizia respeito. As tendências assimilatórias se aprofundavam com o passar dos anos e a narradora penetra por diálogos intergeneracionais, expondo um abismo diferencial entre a geração de princípios do século 21 e suas experiências e sensibilidade, formada entre as tribulações do século 20. No entanto, um casamento dentro dos rituais judaicos, flagrado nas últimas páginas da narrativa, pode simbolizar, num hipotético código metafórico, que o judaísmo terá prosseguimento, uma 
nota aparentemente otimista, que arremata uma narrativa carregada de problemas, obstáculos e negatividades.

É predominante, no decorrer da história, o olhar da imigrante tanto na Europa, para onde foi levada por sua mãe na intenção de chegarem ao Brasil, quanto já no país, como mulher casada. A perspectiva da imigrante é sempre de surpresa, susto, admiração ou acomodação, ainda que esta seja parcial. Nunca é indiferente, mesmo porque a indiferença denotaria fracasso na empreitada de conquistar o momento.

Pode-se dizer que Judite no país do futuro é bem construído para um primeiro livro, e também que Adriana Armony expõe com habilidade certos artifícios literários que podem sinalizar adequado desenvolvimento posterior. No entanto, não se trata de obra de inovação temática, pois segue o roteiro tradicional que inaugurou o componente judaico na literatura brasileira, que é a literatura do campo das memórias liberadas pelo olhar subjetivo dos imigrantes. Neste sentido, a obra de Armony segue a trilha aberta por Scliar, ao reclamar a visão de uma expatriada no seu percurso brasileiro. Condizente com uma tradição recém inaugurada, a da abertura de memórias, Armony percorre uma trilha já conhecida, com este romance que pode ter o qualificativo de "documentário", por guardar dados informativos e documentados, como atesta na sua nota de "Agradecimentos" (Armony 2008: 316-317). Seu valor reside tanto na estrutura ficcional quanto no arcabouço histórico que a sustenta e na honestidade intelectual de incluir dados verossímeis numa linguagem literária.

Viagens, deslocamentos e busca do passado preenchem a narrativa de Tatiana Levy Salem, autora do romance $A$ chave de casa (2007). ${ }^{4}$ Vários eventos se cruzam pelo romance, que relata como a protagonista recebeu e desempenhou a missão de viajar do Rio de Janeiro à Turquia. Ela foi em busca da casa onde o avô morou, em Esmirna, que foi obrigado a abandonar ainda jovem, como tantos o fizeram no seu país e em outros mais, corroídos por uma pobreza incurável. Ele teria trazido consigo a chave da casa e passou-a para a neta. Neste seu primei-

4 A autora nasceu em Lisboa, em 1979, quando seus pais, brasileiros natos, se encontravam refugiados da ditadura brasileira. Para todos os efeitos práticos, ela é brasileira, pois chegou ao Brasil aos nove meses de idade, onde obteve sua nacionalidade. É filha de Helena Salem (1948-1999), que foi prolífica jornalista e autora de obras de cunho político, análises de cinema e artigos jornalísticos. 
ro romance, encontram-se disseminados dados sobre a história pessoal da autora, intercessões na voz imaginada de sua mãe, além das informações históricas cedidas pelo avô turco. É ela quem narra sua viagem, carregando consigo a chave, na intenção de com ela abrir a porta que fora fechada às suas costas pelas maldosas circunstâncias do passado. A essas recordações junta-se um monólogo que passa por dialogo entre a narradora e sua mãe, que também conta sua história de amor, de exílio e "deixa" que sua filha conte como foi sua morte. As várias vozes narradoras se confundem, não há o recurso que se encontra em outras obras, como mudança de sinais gráficos para identificar quem diz o quê. Romance interativo, cabe aos leitores decifrar a autoria da narração, dos pensamentos e das lembranças. Tudo culmina com o retorno da moça da Turquia para o Brasil, depois das suas descobertas como turista e, principalmente, sua autodescoberta - ela mesma foi sua chave, aquela que abriu o seu próprio eu, o contorno de sua fragilidade e também sua força para penetrar no desconhecido. ${ }^{5}$ Mas, essa chave existiu? A chave real tinha ficado na porta da casa, conforme a descrição da partida do avô: "A mãe segurou então a maçaneta e, sem esforço, fechou a porta. Depois girou a chave na fechadura" (Levy 2007: 21). De que chave fala a narradora? Sua metaforização paira por toda a obra. No caminho de retorno ao Brasil, a protagonista permanece uns dias em Portugal, onde tem um breve interlúdio amoroso. Nesse quadro emerge um símbolo, o da multidão ibérica judia em busca do peito lusitano, onde verteu lágrimas e perdeu a vida. Como se fez com os judeus na Inquisição, Portugal não a acolheu. Rejeitada, ela retorna para o Brasil, que tampouco tinha entendido seus pais na sua luta por uma mudança política.

A técnica narrativa de Tatiana Salem parece ser elaborada com extremo cuidado, refletindo seu sentido de responsabilidade como escri-

5 Na história dos judeus, a chave é um emblema bastante conhecido - "la yave de España" é sempre relembrada, como aquela levada pelos espanhóis judeus expulsos de suas casas durante a Inquisição. Por coincidência, no mesmo ano de publicação do romance de Tatiana Salem, saiu na França o romance Elle s'appelait Sarah, que passou ao inglês como Sarah's Key e ao português como A chave de Sarah, pela escritora (com a qual coincide no primeiro nome) Tatiana de Rosnay. A autora, não-judia, relata a trajetória de Sara, menina que ficou com a chave do armário onde seu irmão se escondeu, quando policiais franceses, em colaboração com os nazistas, invadiram sua casa e levaram a mãe e ela para o velódromo transformado em prisão de judeus, no centro de Paris. 
tora. A transição entre história pessoal e relatos sobre seus antepassados, em paralelo com a morte de um ente querido (no caso, a mãe da narradora) permeia uma questão técnica de difícil manejamento em qualquer romance. $\mathrm{O}$ excesso de símbolos e metáforas talvez empanem a trajetória psicológica da narradora, com seus frequentes desvios de memória, estrangulada e fragmentada, interferências e desfocalização temática. A autora, no entanto, tentou solucionar o problema através do artifício de segmentação narrativa, intercalação de imagens e fatos, diálogos parentéticos imaginados e reais, e através de uma metalinguagem, a voz interna da narradora. É um estratagema funcional, onde se percebem influências de autores consagrados - como a da brasileira Helena Parente Cunha no romance Mulher no espelho (1985), sem passar em branco uma possível reminiscência da técnica fragmentária machadiana.

Mais importante, talvez, do que as possíveis influências sofridas pela autora, ou mais também do que as pegadas turísticas da protagonista que abrem um panorama judaico-turco quase inédito na nossa literatura, é a linguagem intimista, que conta a história dos efeitos do tempo na passagem de gerações, das lembranças do que não foi pessoalmente vivido e das reformulações de vidas. As alternâncias observadas - ora a narradora está entrevada, ora está em plena atividade turística - expõe, de maneira simulada, sua multiciplidade. Ora ela é uma diferenciada brasileira na Turquia, ora ela é confundida com uma turca; ora ela é a amante incondicional, ora ela é a jovem temperamental que exige amor sem limites. As oscilações geográficas, mentais e emocionais obedecem ao ritmo da narrativa (ou é a narrativa que segue este metrônomo verbal?). A inominada protagonista revolve um intenso universo particular, explora as possibilidades da humanidade $\mathrm{e}$ mantém-se refém de uma chave, alegoricamente a resposta ou meiaresposta para seus questionamentos existenciais. Sua mãe é sua mentora, num espaço etéreo idealizado, desde que a dor por sua morte prematura (na vida real da autora) nunca foi curada. Sua existência passa a ter o ritmo de maré cheia e maré vazante. Os recursos estilísticos e imagéticos para sua interpretação residem na configuração dos opostos, inércia e movimento. Presa a uma cadeira de rodas, ela é sua mãe, prestes a morrer; voando para a Turquia a bordo de um avião, ela é o pássaro livre à procura da vida. O que sobra nas suas mãos e na sua memória são tanto o amor incondicional que sua mãe teve e ainda 
demonstra nos solilóquios da narradora, quanto a rejeição integral do mundo à sua busca, aos seus devaneios e sofrimentos.

A procura da narradora pela casa do avô baseia-se numa angustiosa recuperação do passado, mas não chega a alcançar o seu resgate, apenas uma remota possibilidade. Ela se imbrica por caminhos diversos que não trazem uma resposta satisfatória, antes pelo contrário, revelam mais uma situação de distanciamento. A sentença que finaliza a múltipla narrativa a expõe pegando na chave empoeirada e entregando-a ao avô, quando ambos permanecem com as "mãos coladas, selando e separando as nossas histórias" (Levy 2007: 206, final).

Mais um escritor desloca o fulcro das ações dos seus personagens além das fronteiras brasileiras. É Leandro Sarmatz, nascido em 1973, jornalista de origem gaúcha que, na altura desta escrita, trabalha e mora em São Paulo. Parte das narrativas que compõem seu livro de contos Uma fome se faz dentro do conceito de linearidade, outra parte se guia pelo fluir da consciência, como interpretada por palavras aparentemente em roldão (Sarmatz 2010a). Neste último arranjo insere-se "Uma fome" (homônimo ao título do livro), por onde se misturam anotações mentais que descrevem passagens da infância do narrador, imagens de paisagens desfiguradas pelo tempo, nomes de escritores, políticos e outros famosos, retalhos da história do Brasil na década dos anos 60, decisões pessoais, registro de ciclos comemorativos judaicos, referências à morte trágica de uma irmã, e assim por diante. ${ }^{6} \mathrm{~A}$ narrativa retira de cada canto da memória e do acervo de conhecimento do protagonista um motivo para imbricar mais uma palavra, um termo, uma sentença. $\mathrm{O}$ fio condutor do monólogo é a ansiedade do narrador em manter seu peso físico, em desviar-se das tentações gastronômicas, evitar as doenças que mataram seus parentes e permanecer dentro de um regime dietético. O que ele deseja é manter-se esbelto - esbeltez que quer fazer transbordar para sua escrita, como observa: "Já faz algum tempo que venho tentando estabelecer as ligações entre magreza e literatura. [...] Penso muito na questão" (Sarmatz 2010a: 75). A fixidez mental por seu contorno físico e por uma narrativa reduzida a osso e carne, isenta de extravagâncias, paradoxalmente não evita que o conto seja um tanto inflado por um remoinho de palavras, apesar de o

6 O mesmo conto faz parte da coletânea Primos. Histórias da herança árabe e judaica (Sarmatz 2010b). 
autor pretender "ficar no essencial, depurar toda forma de excesso" (Sarmatz 2010a: 76).

Na primeira parte do livro, que está dividido em duas - " 1 . Atores" e "2. Abandonos" — os seus contos são mais lineares, menos inflados e, portanto, mais "esbeltos". O imaginário afasta-se do Brasil e penetra pelos escombros do Holocausto, como em "O pequeno Junger" - história de um ator alemão que se vê forçado a adotar um menino, filho de pai judeu, nas vésperas do genocídio; o garoto, desconhecendo sua verdadeira origem, acaba se tornando um portavoz da juventude hitlerista, chegando a trabalhar no cinema de propaganda, antes de ser recrutado pelo exército nazista. No conto, tal itinerário de vida do protegido terá uma influência determinante na vida do seu protetor.

A sensibilidade de Sarmatz quanto às vítimas do Holocausto insere mais duas histórias nessa mesma parte, "Harry Abbott" e "O conde". Pelas três narrativas curtas que a compõem, o autor se lança em território literário já percorrido por outros que, como ele, não foram vítimas diretas daquele período, mas possivelmente o são indiretamente - através de antecedentes que pereceram nas garras dos nazistas. Esses escritores são "testemunhas pela imaginação", pelo impacto daquele período que, como em Sarmatz, se arraigou no espírito dos que nasceram depois do término do conflito (Kremer 1989: 8). Já influenciado por algumas das consequencias dos assassinatos nazistas, o autor intitulou seu primeiro livro (de poemas) de Logocausto, um claro desvio intencional e irônico do termo "holocausto", onde o poeta lamenta o desaparecimento do idioma ídiche (Sarmatz 2010c). ${ }^{7}$

Como dramaturgo, Sarmatz tem no seu acervo a peça Mães \& Sogras, que explora clichês acumulados numa família judia na qual um dos filhos está casado com uma moça não-judia (Sarmatz 2000). Ao satirizar certos cacoetes comportamentais de elementos da comunidade judaica, e correndo o risco de que tais estereótipos sirvam como evidências naturais, a peça ganhou leituras dramáticas e encenações, tanto em palco gaúcho quanto paulistano.

7 "Logo", do grego: "palavra", daí "logocausto" referir-se, por dedução, ao desaparecimento da comunicação tradicional entre os judeus do leste da Europa, o ídiche. 
Ainda pouco conhecido do público leitor, Sarmatz apresenta um veio satírico na maior parte dos seus escritos. Percebe-se nele um potencial que, desenvolvido, mostrará um escritor brasileiro judeu relacionado tanto à realidade contemporânea quanto aos aspectos tradicionais do judaísmo, como sociedade imbricada num meio não-judaico.

Outro gaúcho emergindo no panorama literário brasileiro judaico dos últimos dez anos, é Rafael Bán Jacobsen $\left({ }^{*} 1981\right){ }^{8}$ Aos 17 anos de idade, publicou Tempos \& costumes (1998), pelo qual recebeu Menção Honrosa da entidade sulina Prêmio Açorianos de Literatura. Seu romance Solenar (2005) também foi agraciado pelo mesmo prêmio, anos mais tarde. Sua vida profissional se divide entre ser pianista, escritor e pesquisador de Cosmologia e Física Nuclear e de Partículas, na Universidade Federal do Rio Grande do Sul. Tem orgulho de ser vegetariano e nesta condição, participa de eventos onde faz comunicações sobre os direitos dos animais e sobre escritores universais vegetarianos.

É também profundamente conhecedor e entrosado com a cultura judaica e a literatura bíblica, como se revela no seu romance Uma leve simetria (no original, a palavra "leve" está em tipo itálico, isto é, grifada) (Jacobsen 2009). Um glossário ao final do livro enlista os termos transliterados do hebraico e do ídiche que se encontram na narrativa. Esta é bifurcada entre a história bíblica e ambígua de Jonatã e David e a história de Pedro e Daniel, como narrada pelo último, localizada na sociedade brasileira. Cada capítulo é numerado por uma letra do alfabeto hebraico, encimado por um Salmo (119) em português e intercalado por trechos da Bíblia referentes à amizade entre David (aquele que derrotou Golias) e Jonatã, filho do rei Saul (conforme o Livro de Samuel). A possibilidade de que esses dois personagens bíblicos tivessem um afeto homoerótico ou homossexual (ou nenhum desses) flutua pelas pesquisas de historiadores. O amor de Daniel por Pedro é uma verdade incontestável na armação do romance de Jacobsen, que revela

8 Em entrevista à revista Wizo do Rio Grande do Sul (cedida pelo autor, mas sem registro de data), Rafael explica a origem de seu sobrenome, incomum entre imigrantes judeus no Brasil: "Minha família é de origem judaica tanto pelo lado materno quanto pelo paterno. Os Jacobsen, judeus dinamarqueses, chegaram à América na segunda metade do século XIX. Já os Spitz Bán são judeus húngaros, chegaram no período entre-guerras". 
não só impulsos explosivos e contenções milimetradas, como também os problemas incontornáveis que impedem o usufruir dos seus sentimentos. A religião judaica proíbe, como as duas outras monoteístas, que o amor homossexual seja consumado, como faz lembrar o rabino que o protagonista foi consultar: "Mas o que o rabino Levi disse, a seguir, aniquilou o pouco de mim que ainda lutava: se olharmos friamente para a Lei, nada impede o gostar; contudo, a realização é vedada" (Jacobsen 2009: 66). ${ }^{9}$

O capítulo que antecede o primeiro (que se inicia pela letra "alef" do alfabeto hebraico) é precedido pela citação, em hebraico, de uma das ordens ditadas no Levítico (19: 22): "Com varão te não deitarás, como se fosse mulher; abominação é". Mas não é só a religião que vai intervir nos laços emocionais entre os dois rapazes. $\mathrm{O}$ romance de Jacobsen revela as limitações existentes num entorno urbano e moderno, sem especificar qual seja, através do protagonista-narrador que explora suas camadas preconceituosas, que the parecem tão densas quanto as proibições milenárias. Como o romance de Cíntia Moscovich, Duas Iguais (1998), este também esquadrinha as amarras sociais visíveis na comunidade judaica e na sociedade em geral.

Um livro calmo e flamejante, ainda que pareça paradoxal a inserção desses dois adjetivos díspares. O romance de Jacobsen avalia tanto o sentimento amoroso quanto a solidão, a exaltação pela vida e o desespero pela morte. Entre essas emoções, no entanto, parece ser a solidão a sensação mais burilada pelo autor, num trabalho estatuário verbal meticuloso e cabal. A escrita se envolve ou é envolvida por cânticos bíblicos e poemas, talvez numa evocação gráfica do lirismo davidiano e da atmosfera que envolveu Jonatã e David, e que Daniel quis trazer à sua amizade com Pedro. Estaria neste paralelismo a 'leve' simetria indicada no título. Esta obra, de superior contribuição à literatura brasileira, tanto no plano linguístico quanto no campo do homoerotismo, faz um tributo a Clarice Lispector, ao reproduzir, em seus próprios termos, o jogo de títulos, que a escritora colocou em $A$ hora da estrela (1977). Os títulos propostos por Jacobsen, em número de 12 , comprimem a narrativa num índice esclarecedor, como: "Uma

9 O fato de o rabino ser chamado de 'Levi' não pode passar despercebido, pois é no Levítico que se estabelecem as principais proibições inseridas na religião judaica. 
leve simetria ou Crônica de um amor desesperado ou $\mathrm{O}$ inverso do triângulo ou Estrelas vazias ou O último salmo de David", etc., dispostos verticalmente contra um fundo negro.

O talento literário de Jacobsen, como visto nesta obra em particular, é incontestável, pelo valor que ele atribui à língua portuguesa, aplicando um conhecimento refinado e profundo na modelagem das suas sentenças e parágrafos na prosa, e na musicalidade dos poemas. Pela escolha do tema, que pede um tatear delicado e sutil, que é facilmente encontrado nas suas páginas, o autor só pode ser considerado um escritor de sensibilidade e humanidade.

Nem todos os escritores brasileiros judeus optaram por inserir a cultura judaica nos seus escritos, como se pode observar nas obras dos gaúchos Carol Bensimon e Michel Laub, e do carioca Michel Melamed. Em correspondência pessoal, Carol se definiu como "atéia":

Toda minha família é atéia, embora eu tenha crescido em meio a jantas de pessach e rosh hashana, que sempre mantivemos pela "tradição" (mas jamais fui no bar mitzvah de alguém). Eu me sinto, é claro, porque entendo o 'ser judeu' como algo que vai além da religião [...] De qualquer maneira, a minha literatura - ou pelo menos até agora - não traz questões tão implicitamente judaicas como, pensando em alguns conterrâneos meus, a obra de Cíntia Moscovich e Moacyr Scliar. Não escrevo sobre judaísmo, sou uma judia escrevendo, isso é tudo. ${ }^{10}$

Como Carol, Michel Laub também nasceu em Porto Alegre (1973). Formado em jornalismo, tem uma sólida carreira na imprensa brasileira, além de atuar como professor de criação literária numa instituição paulistana. Tem quatro romances publicados e foi recipiente do Prêmio Erico Verissimo/Revelação, da União Brasileira dos Escritores, além de ter sido finalista dos prêmios Jabuti, Portugal Telecom (duas vezes), entre outros. Entrei em contato com ele pela internet, fiz-lhe perguntas sobre sua ascendência judaica, e ele respondeu com muita cortesia precisão sobre sua árvore genealógica. No entanto, não respondeu às questões sobre judaísmo ou sua ausência no corpo do seu material ficcional, o que não deixa de ser interessante também.

Outro jovem de origem judaica e de projeção nacional é Michel Melamed, natural do Rio de Janeiro (1976). Mais conhecido nos mei-

10 Carol Bensimon nasceu em Porto Alegre, em 1982. É descendente de judeus sefarditas. Sua família é de Alexandria, Egito, de onde saíram para o Brasil em 1957. O texto acima está em e-mail enviado pela autora. Com data de quartafeira, $1^{\circ}$ de julho, 2009, 12:24:34 EDT - (e-mail suprimido). 
os de teatro e televisão, seu livro Regurgitofagia é uma consequência de seu talento para o espetáculo público (Melamed 2005). Condensa, na escrita, linguagem teatral, expressão poética, senso de humor, vários graus de ironia e certas aplicações de artes gráficas. No que diz respeito ao judaísmo explícito do autor nas suas obras, ele deve estar numa linha fronteiriça. Enquanto o conjunto gráfico e expressionista de seu livro não inclui o fator judaico como ponto central, o escritor insere uma nota autobiográfica que revela, em tom zombeteiro:

Ser pisciano, judeu, poeta e carioca e correntista do Itaú é - além da pulga como orelha - viver o eterno e generalizado déjà vu. ... Você, que é um taurino, católico, dentista e baiano - correntista da Caixa; ou uma libriana, muçulmana, publicitária e gaúcha - Banco Sandy Junior; até mesmo um leonino, ateu, ator e paulista - Bank de Boston, saiba: é muito estranho ser um pisciano, judeu, poeta e carioca - correntista do Itaú. Ter a sensação de que tudo que acaba de dizer, já foi dito. Foi pensado. Esquecido (Melamed 2005: 100).

Não se trata, aqui, nem caberia, uma cobrança aos escritores de origem judaica. Trata-se não mais do que um registro sobre os mesmos que, surgindo dessa comunidade no Brasil, digamos que, ao menos literariamente, preferem mostrar-se assimilados. Sem arguições pró e contra, é lícito observar que se trata de uma escolha tão legítima quanto a outra, a de inserir convivência e temas judaicos na sua obra ficcional.

$\mathrm{Na}$ avaliação conclusiva a respeito do grupo recém surgido de escritores brasileiros judeus, pode-se lembrar um arquétipo, que seria a história do Chapeuzinho Vermelho. Esta lenda, como se sabe, recebeu e ainda recebe inúmeras interpretações, tanto freudianas, como junguianas, antropológicas, históricas, folclóricas, etc. Como sabemos, é a história que envolve a mãe de uma menina que lhe dá o encargo de levar comida para a avó, que está doente e que mora além da floresta. Também lhe diz que evite o bosque e que siga diretamente pelo caminho mais conhecido. $\mathrm{O}$ resto, já se sabe: ela não obedece, vai pela floresta, é interceptada pelo lobo, etc.

Como as histórias das lembranças judaicas se referem a esse perfil arquetípico? Nas histórias que inserem temática judaica aqui revistas, percebe-se um motivo constante: a volta ao passado. É a geração de hoje que retorna, que procura, que tenta impregnar-se dos sabores do passado, ou se arrasta até ele em busca de sua identidade pessoal, já que a nacional the é de direito de nascença. Assim como a mãe da 
Chapeuzinho Vermelho lhe deu um lanche para alimentar a avó, esta geração de escritores recebe de seus pais a convivência judaica suficiente e bastante para que alimente, por lembranças e outros meios, como viagens e procuras mapeadas, a casa dos antepassados. É uma questão de uma geração intermédia - os pais — incentivar a mais jovem (os filhos) a manter a geração anterior viva no plano das lembranças (e da imitação).

Tanto Cíntia Moscovich quanto Tatiana Salem Levy se fizeram de Chapeuzinho Vermelho a caminho da casa de um/a antepassado/a. Já na narrativa de Adriana Armony, a Judite do romance é a própria avó, pois é ela quem conta sua história e é ela quem espera ser alimentada pelas gerações sucessivas (mas, para seu desencanto, seus netos a negligenciam e pouco se inclinam ao judaísmo como ela o praticava). Aplicando a mesma alegoria à obra de Rafael Bán Jacobsen aqui examinada, o que se percebe é a intolerância da "avó"... Se "ela", neste quadro de símbolos, passa a representar os ditames religiosos consagrados pelos tempos e pela sociedade, é "ela" quem rejeita as oferendas de amor e cuidado dos seus descendentes, por não obedecerem aos seus parâmetros. A "avó" - a Bíblia, a sociedade, a interpretação que a mesma faz dos escritos bíblicos — não tolera a transgressão. Daí a recusa em aceitar o homoerotismo (talvez como um lanche indigesto).

Os jovens escritores brasileiros judeus (a maior parte deles nascida entre 1970 e 1980) examinados aqui contribuem para o acervo literário do país com uma gama de conflitos, tramas, fabulações, inseridos na comunidade judaica. Todos descendentes de imigrantes, afastam-se dos temas tradicionalmente levantados por aqueles e se lançam por histórias novas, como seria de se esperar, baseadas em sua própria vivência. Escritores escolarizados e educados no Brasil, são amantes da língua portuguesa, pelos cuidados que mostram na lealdade a seus recursos. Alguns resgatam temas já aprofundados na literatura brasileira em geral e na judaica também, mas trazem novo fôlego e vibrações inéditas aos mesmos. É um quadro composto por profissionais da escrita, que querem ser lidos e comentados, esforçando-se em expor literariamente o que de melhor podem oferecer dentro do conhecimento e ótica individuais. 


\section{Bibliografia}

Armony, Adriana ([2005] 2008): Judite no país do futuro. Rio de Janeiro: Editora Record.

Bíblia Sagrada $\left({ }^{10} 1956\right)$. Edição revista e corrigida. João Ferreira de Almeida (traductor). Rio de Janeiro: Imprensa Bíblica Brasileira.

Igel, Regina (1997): Imigrantes judeus - escritores brasileiros. O componente judaico na literatura brasileira. São Paulo: Ed. Perspectiva.

- (2000): "Escritores judeus brasileiros, um percurso em andamento". Em: Revista Iberoamericana, 66, 191, pp. 325-338.

Jacobsen, Rafael Bán (2009): Uma leve simetria. Porto Alegre: Não editora.

Kremer, S. Lillian (1989): "Preface". Em: Kremer, S. Lillian: Witness through the Imagination: Jewish American Holocaust Literature. Detroit: Wayne State University Press, pp. 7-12.

Levy, Tatiana Salem (2007): A chave de casa. Rio de Janeiro: Editora Record.

Melamed, Michel (2005): Regurgitofagia. Rio de Janeiro: Objetiva.

Moscovich, Cíntia (1996): O reino das cebolas: contos e narrativas. Porto Alegre: Prefeitura Municipal/Fumproarte/Mercado Aberto.

- (2000): Anotações durante o incêndio. Porto Alegre: L\&PM.

Ribeiro, Joaquim (1977): Os brasileiros. Rio de Janeiro: Pallas SA/Editora e Distribuidora e Instituto Nacional do Livro/Ministério da Educação e Cultura.

Sarmatz, Leandro (2000): Mães \& sogras. Tragicomédia em três atos. Porto Alegre: Instituto Estadual do livro/CORAG.

- (2010a): Uma fome. Rio de Janeiro: Editora Record.

- (2010b): "Uma fome”. Em: Armony, Adriana/Levy, Tatiana Salem (eds.): Primos. Histórias da herança árabe e judaica. Rio de Janeiro: Editora Record, pp. 117-140.

- (2010c): Logocausto. São Paulo: Editora da Casa.

Scliar, Moacyr (2000): "Memórias judaicas". Em: Scliar, Moacyr et al.: Entre Moisés e Macunaíma. Rio de Janeiro: Editora Garamond, pp. 23-84. 